\title{
Physical Properties of Carboxymethyl Cellulose from Palm Bunch and Bagasse Agricultural Wastes: Effect of Delignification with Hydrogen Peroxide
}

\author{
Rungsiri Suriyatem ${ }^{1}$, Nichaya Noikang ${ }^{2}$, Tamolwan Kankam ${ }^{2}$, Kittisak Jantanasakulwong ${ }^{2,3,4}$, \\ Noppol Leksawasdi ${ }^{2,3,4}$, Yuthana Phimolsiripol 2,3,4 (D), Chayatip Insomphun 2,3, \\ Phisit Seesuriyachan ${ }^{2,3}$, Thanongsak Chaiyaso ${ }^{2,3}$, Pensak Jantrawut ${ }^{3,5}{ }^{-0}$, \\ Sarana Rose Sommano ${ }^{3,6}{ }^{(\mathbb{B}}$, Thi Minh Phuong Ngo $^{7}$ and Pornchai Rachtanapun ${ }^{2,3,4, *(\mathbb{C})}$ \\ 1 Division of Cosmetic Science and Health Products, School of Pharmacy, Eastern Asia University, \\ Pathum Thani 12110, Thailand; rungsiri@eau.ac.th \\ 2 School of Agro-Industry, Faculty of Agro-Industry, Chiang Mai University, Chiang Mai 50100, Thailand; \\ nichaya.aong@gmail.com (N.N.); tamolwan.aumaim@gmail.com (T.K.); \\ jantanasakulwong.k@gmail.com (K.J.); noppol@hotmail.com (N.L.); yuthana.p@cmu.ac.th (Y.P.); \\ chayatip@yahoo.com (C.I.); phisit.s@cmu.ac.th (P.S.); thachaiyaso@hotmail.com (T.C.) \\ 3 The cluster of Agro Bio-Circular-Green Industry (Agro BCG), Chiang Mai University, \\ Chiang Mai 50100, Thailand; pensak.amuamu@gmail.com (P.J.); sarana.s@cmu.ac.th (S.R.S.) \\ 4 Center of Excellence in Materials Science and Technology, Chiang Mai University, \\ Chiang Mai 50200, Thailand \\ 5 Department of Pharmaceutical Sciences, Faculty of Pharmacy, Chiang Mai University, \\ Chiang Mai 50200, Thailand \\ 6 Plant Bioactive Compound Laboratory (BAC), Department of Plant and Soil Sciences, Faculty of Agriculture, \\ Chiang Mai University, Chiang Mai 50200, Thailand \\ 7 Department of Chemical Technology and Environment, The University of Danang-University of Technology \\ and Education, Danang 550000, Vietnam; ntmphuong@ute.udn.vn \\ * Correspondence: pornchai.r@cmu.ac.th or rachtanapun.r@gmail.com; Tel.: +666-354-925-56; \\ Fax: +665-394-8224
}

Received: 21 May 2020; Accepted: 9 June 2020; Published: 7 July 2020

\begin{abstract}
The aim of this work was to synthesize carboxymethyl cellulose $(\mathrm{CMC})$ and produce $\mathrm{CMC}$ films from the cellulose of palm bunch and bagasse agricultural waste. The effect of various amounts of $\mathrm{H}_{2} \mathrm{O}_{2}(0-40 \% v / v)$ during delignification on the properties of cellulose, $\mathrm{CMC}$, and CMC films was studied. As the $\mathrm{H}_{2} \mathrm{O}_{2}$ content increased, yield and the lignin content of the cellulose from palm bunch and bagasse decreased, whereas lightness $\left(L^{*}\right)$ and whiteness index (WI) increased. FTIR confirmed the substitution of a carboxymethyl group on the cellulose structure. A higher degree of substitution of CMC from both sources was found when $20 \%-30 \% \mathrm{H}_{2} \mathrm{O}_{2}$ was employed. The trend in the $L^{*}$ and WI values of each CMC and CMC film was related to those values in their respective cellulose. Bleaching each cellulose with $20 \% \mathrm{H}_{2} \mathrm{O}_{2}$ provided the cellulose with the highest viscosity and the CMC films with the greatest mechanical (higher tensile strength and elongation at break) and soluble attributes, but the lowest water vapor barrier. This evidence indicates that cellulose delignification with $\mathrm{H}_{2} \mathrm{O}_{2}$ has a strong effect on the appearance and physical properties of both CMCs.
\end{abstract}

Keywords: bleaching; carboxymethylation; cellulose; CMC film; lignin; viscosity

\section{Introduction}

Carboxymethyl cellulose (CMC) is one of the most important cellulose derivatives. A large amount of commercial CMC is used in various applications such as ceramic foam [1], paper [2], textiles [3], 
pharmaceutics [4], food [5], and biodegradable films [6,7]. CMC is derived from cellulose, which is non-toxic to human health. Cellulose is commonly found in plant cell walls. It is usually conjunct with hemicellulose and lignin. The variety of plant affects the composition and the cellulose content. The other substances, especially lignin, also make it difficult to obtain pure cellulose. To get rid of lignin, numerous oxidizing agents are used in most lignocellulosic materials for bleaching [8-11]. They are categorized as chlorine compounds and non-chlorine compounds. Among all of them, there are just a few eco-friendly reagents. Hydrogen peroxide $\left(\mathrm{H}_{2} \mathrm{O}_{2}\right)$ is one of the commercial reagents used in environmentally friendly and energy-saving bleaching systems $[9,12]$. Different cellulose sources have been reported to implement $\mathrm{H}_{2} \mathrm{O}_{2}$ into the bleaching treatment, such as papaya peel [12], durian rind [9], oil palm empty-fruit-bunch [13], and cotton [14]. In addition, some studies have reported the influence of oxidizing agent concentration on the properties of the final products of various cellulose sources such as pure cellulose and paper [15], olive tree branch [16], and rice husk [17].

Nowadays, sustainable and ecological materials are the subject of global focus with constant growing interest. Agricultural waste is a cellulose source which is cheap, various and abundant. In literature, many research has studied the synthesis of CMC from agricultural waste cellulose sources. The examples include CMC from sugar beet pulp [18], cavendish banana pseudostem [10], cotton linters [19], sago waste [20], papaya peel [12], mulberry paper [21], corn husk [22], Mimosa pigra peel [23], and durian rind [9,24].

Until today, there has not been any research on the effect of delignification with $\mathrm{H}_{2} \mathrm{O}_{2}$ on the physical properties of cellulose and $\mathrm{CMC}$ from palm bunch and bagasse agricultural wastes, including their $\mathrm{CMC}$ films. Therefore, the present study aimed to demonstrate the influence of bleaching cellulose with $\mathrm{H}_{2} \mathrm{O}_{2}$ on the properties of cellulose, $\mathrm{CMC}$ and $\mathrm{CMC}$ films from palm bunch and bagasse. The cellulose and lignin contents of the raw materials were determined. The percent yield, lignin content, optical properties, morphology, and chemical structure of the bleached cellulose was evaluated. In addition, the percent yield, degree of substitution, optical properties, viscosity, morphology, and chemical structure of the CMCs were investigated. Moreover, the optical and mechanical properties, solubility, and water vapor transmission rate of the CMC films were investigated.

\section{Materials and Methods}

\subsection{Materials}

Palm bunch was collected from the palm garden in Chiang Mai Floraville Village (Chiang Mai, Thailand). Bagasse was obtained from a local sugarcane juice shop at Central Plaza Chiang Mai Airport (Chiang Mai, Thailand). Sodium hydroxide and glacial acetic acid were purchased from Merck (Darmstadt, Germany). Monochloroacetic acid was purchased from Sigma Aldrich (Steinhiem, Germany). Hydrogen peroxide, glycerol, ethanol, and methanol were purchased from Northern Chemicals and Glasswares Ltd., Part. (Chiang Mai, Thailand). All reagents were of analytical grade and used as received.

\subsection{Sample Preparation}

Palm bunch and bagasse were cut into pieces of $20 \mathrm{~mm}$ length, sun-dried for around two days and further dried at $60^{\circ} \mathrm{C}$ in an oven for $24 \mathrm{~h}$. The dried samples were ground into powder using a hammer mill (Armfield, England). The cellulose and lignin contents of the raw materials were determined according to TAPPI (Technical Association of the Pulp and Paper Industry) standard methods T $203 \mathrm{~cm}-09$ [25] and T $222 \mathrm{om}-15$ [26], respectively. Shortly afterwards, sample powder (3 g), distilled water $(160 \mathrm{~mL})$, glacial acetic acid $(0.5 \mathrm{~mL})$, and sodium chloride $(1.5 \mathrm{~g})$ were mixed in a beaker and stirred continuously for $1 \mathrm{~h}$ at $80^{\circ} \mathrm{C}$. The beaker was cooled to $10^{\circ} \mathrm{C}$, filtered, and washed with acetone. The product was dried in an oven for $24 \mathrm{~h}$ at $80^{\circ} \mathrm{C}$. Cellulose content (\%) was calculated by multiplying the ratio of product weight/sample weight by 100 . In order to determine lignin content, in brief, sample powder $(1 \mathrm{~g})$ was placed in a beaker at $2{ }^{\circ} \mathrm{C}$. Cold $\left(10-15^{\circ} \mathrm{C}\right)$ sulfuric acid $(72 \%$, 
$15 \mathrm{~mL}$ ) was gradually introduced, and the mixture was continuously stirred for $2 \mathrm{~h}$. Distilled water $(560 \mathrm{~mL})$ was added. The mixture was boiled for $4 \mathrm{~h}$ and left standing to allow precipitation overnight. The mixture was filtered, washed with water three times, and dried in an oven for $6 \mathrm{~h}$ at $105^{\circ} \mathrm{C}$. The final product was later weighed. The lignin content (\%) was calculated by multiplying the ratio of product weight/sample weight by 100 .

\subsection{Cellulose Extraction and Bleaching}

Cellulose from palm bunch and bagasse was extracted and bleached according to the method described by Rachtanapun et al. [9]. In brief, the pulp samples (10 g) were mixed with $30 \% w / v \mathrm{NaOH}$ $(100 \mathrm{~mL})$ in a beaker. The mixture was heated to $100^{\circ} \mathrm{C}$, stirred continuously for $3 \mathrm{~h}$ and filtered. The solid phase was rinsed with distilled water several times until the remaining water was clear. The cellulose pulp was dried in an oven at $55^{\circ} \mathrm{C}$ for $24 \mathrm{~h}$. The dried pulp $(10 \mathrm{~g})$ was subjected to bleach with various concentrations of $\mathrm{H}_{2} \mathrm{O}_{2}$ solution $(0 \%, 10 \%, 20 \%, 30 \%$, and $40 \% v / v)$ in a hot water bath at $80^{\circ} \mathrm{C}$ for $2 \mathrm{~h}$. Finally, the bleached pulp was rinsed with distilled water to remove the residual lignin and dried in an oven at $55^{\circ} \mathrm{C}$ for $24 \mathrm{~h}$. The percent yield of the cellulose products was calculated using Equation (1):

$$
\text { Yield of cellulose }(\%)=\frac{W_{a}}{W_{b}} \times 100
$$

where $W_{a}$ and $W_{b}$ were the weight of cellulose after and before bleaching, respectively. The Kappa number $(K)$ was applied in this work according to TAPPI standard method T 236 om-99 [27] to determine the bleaching ability or degree of delignification of the pulp. Briefly, the pulp $(3 \mathrm{~g})$ was suspended in distilled water $(500 \mathrm{~mL})$ with continuous stirring for $5 \mathrm{~min}$ at $25^{\circ} \mathrm{C}$. The addition of $0.1 \mathrm{M}$ potassium permanganate $(100 \mathrm{~mL})$ and $4 \mathrm{M}$ sulfuric acid $(100 \mathrm{~mL})$ was later performed, and the mixture was then stirred continuously for $5 \mathrm{~min}$. Distilled water was added to achieve a total volume of $1.0 \mathrm{~L}$, and the mixture was constantly stirred for $10 \mathrm{~min}$. The cessation of the reaction was achieved with the addition of $1 \mathrm{M}$ potassium iodide $(20 \mathrm{~mL})$. Immediately, the free iodine in the mixture was titrated with $0.2 \mathrm{M}$ sodium thiosulfate. A few drops of starch solution were used as an indicator. The $\mathrm{K}$ value was calculated using the equation described elsewhere [27]. The approximate lignin level (\%) of the bleached cellulose samples was calculated using Equation (2) [27]:

$$
\text { Lignin }(\%)=K \times 0.13
$$

\subsection{Synthesis of CMC}

Before synthesis, the bleached cellulose from palm bunch and bagasse was ground into a fine powder (under 60 mesh) using an Ultra centrifugal mill ZM 200 (RETSCH, Germany). The cellulose was converted to CMC according to the method described by Rachtanapun et al. [9]. Cellulose (15 g), $40 \% w / v \mathrm{NaOH}(50 \mathrm{~mL})$ and isopropanol (IPA, $450 \mathrm{~mL}$ ) were mixed and continuously stirred in a beaker at $50^{\circ} \mathrm{C}$ for $1 \mathrm{~h}$. The mixture was gradually supplemented with the solution of chloroacetic acid/IPA (18 g: $18 \mathrm{~mL}$ ), further stirred for $30 \mathrm{~min}$ and placed in an oven at $55^{\circ} \mathrm{C}$ for $3.5 \mathrm{~h}$. The liquid phase of the mixture was removed. The solid phase was mixed with methanol $(225 \mathrm{~mL})$ and neutralized with glacial acetic acid. The mixture was filtered and rinsed with $70 \% v / v$ ethanol $(225 \mathrm{~mL}) 5$ times and a final time with $95 \% v / v$ methanol $(225 \mathrm{~mL})$. The last product, $\mathrm{CMC}$, was dried in an oven at $55^{\circ} \mathrm{C}$ for $12 \mathrm{~h}$ and kept in a polyethylene bag until being used. The percent yield of the CMC was calculated using Equation (3):

$$
\text { Yield of } \mathrm{CMC}(\%)=\frac{W_{C M C}}{W_{c}} \times 100
$$

where $W_{C M C}$ was the weight of synthesized CMC; $W_{c}$ was the weight of cellulose. The degree of substitution (DS) of the CMC was measured using the USP XXXII method described for croscarmellose sodium, the procedure of which was described elsewhere [23]. 


\subsection{Characterization of Cellulose and CMC Powder}

The lightness $\left(L^{*}\right)$ value of the cellulose and CMC samples was measured using a colorimeter (CR-400, Konica Minolta, Shanghai, China). Sample powder (2 g) was set in a sample holder placed above the instrument. The testing button was pressed, and the $L^{*}$ value was shown on the result screen. Each test was run in triplicate. The whiteness index (WI) value was calculated using a method described elsewhere by the authors [28].

Morphological investigation of the cellulose and CMC samples was performed using a scanning electron microscope, SEM (Quanta 200 3D, FEI, Hillsboro, OR, USA). The samples were adhered to carbon tape containing a specimen stub and sputter-coated with a thin layer of gold using a sputter coater (SPI-Module, Wilmington, MA, USA). The observation was run on a voltage of $15 \mathrm{kV}$ with $1000 \times$ magnification.

An FTIR spectrometer (Tensor 27, Bruker, Ettlingen, Germany) was used to provide transmission infrared spectra of the samples. A pellet of each sample was mounted directly in the pellet holder. The test was run in the range of $4000-400 \mathrm{~cm}^{-1}$, with a resolution of $4 \mathrm{~cm}^{-1}$. Before the test, pellets of the samples were prepared by mixing and pressing the samples $(\sim 2 \mathrm{mg})$ with $\mathrm{KBr}$.

A Rapid Visco Analyzer (RVA-4, Newport Scientific, Jessup, MD, USA) was used to measure the viscosity of the CMC samples. CMC $(3 \mathrm{~g})$ was dissolved in distilled water $(25 \mathrm{~mL})$ at $80^{\circ} \mathrm{C}$ for $10 \mathrm{~min}$. The CMC solution was poured into the test cup and placed in the sample holder. Initially, the speed of testing was set at $960 \mathrm{rpm}$, for $10 \mathrm{~s}$ at $30^{\circ} \mathrm{C}$. Afterwards, the temperature was varied $\left(30,40\right.$, and $\left.50^{\circ} \mathrm{C}\right)$ for $6 \mathrm{~min}$ with a speed of $160 \mathrm{rpm}$. All measurements were run in triplicate.

\subsection{Preparation of CMC Films}

To prepare the CMC film, CMC (3 g), distilled water $(100 \mathrm{~mL})$, and glycerol $(0.9 \mathrm{~g})$ were mixed in a beaker, heated to $80^{\circ} \mathrm{C}$, and continuously stirred for $10 \mathrm{~min}$. The mixture was cooled to $25^{\circ} \mathrm{C}$, cast on an acrylic plate, and dried in an oven at $40^{\circ} \mathrm{C}$ for $24 \mathrm{~h}$. The dried film was peeled and kept at $25{ }^{\circ} \mathrm{C}, 52 \pm 1 \% \mathrm{RH}$ (relative humidity) in a desiccator until testing. The thickness of the films was measured using a micrometer model GT-313-A (Gotech Testing Machine Inc., Taichung, Taiwan).

\subsection{Properties of CMC Films}

The $L^{*}$ and WI of the film samples were measured using the same method as described above in Section 2.5. The test was run in triplicate.

Tensile properties (tensile strength, TS, and elongation at break, EB) were determined according to ASTM (American Standard for Testing and Materials) D882-12 [29]. The film was cut into ten rectangular specimens $(15 \mathrm{~mm} \times 150 \mathrm{~mm})$ and tested using a Universal Testing Machine Model 1000 (Instron corp., Canton, MA, USA). The initial grip separation and the speed of the test were set at $100 \mathrm{~mm}$ and $10 \mathrm{~mm} / \mathrm{min}$, respectively.

To measure water solubility, the film was cut into a square shape (20 $\mathrm{mm} \times 20 \mathrm{~mm})$. The film specimen was soaked in distilled water $(50 \mathrm{~mL})$ and shaken continuously for $2 \mathrm{~h}$. The residue was filtered and dried in an oven at $105^{\circ} \mathrm{C}$ for $24 \mathrm{~h}$. The test was applied in triplicate. The solubility of the film samples was calculated using Equation (4):

$$
\text { Solubility }(\%)=\frac{W_{1}-W_{2}}{W_{1}} \times 100
$$

where $W_{1}$ was the weight of the sample before testing; $W_{2}$ was the weight of the dried residual.

The water vapor transmission rate (WVTR) of the CMC films was measured according to ASTM-E96/E9M-16 [30] using a cup method. Each CMC film sample was prepared by cutting it into a circle $(\varnothing \approx 8 \mathrm{~cm})$. The test cup was filled with dried silica gel $(10 \mathrm{~g})$, covered with a film sample and sealed with paraffin wax. The cup was weighted and placed in a desiccator at $25{ }^{\circ} \mathrm{C}, 52 \pm 1 \% \mathrm{RH}$. The cup was weighted every $24 \mathrm{~h}$ for 7 days. The WVTR of the films was calculated using Equation (5): 


$$
\mathrm{WVTR}=\text { slope } / A
$$

where slope was obtained from the linear curve of the plot between weight gain (y axis) and time (x axis); $A$ was the area of the specimen.

\subsection{Statistical Analysis}

Data were analyzed using SPSS software (Version 11, SPSS Inc., Chicago, IL, USA). One-way analysis of variance (ANOVA) and Duncan's multiple range test $(p \leq 0.05)$ were carried out.

\section{Results}

The cellulose and lignin contents of the raw materials were determined. It was found that palm bunch had $29.3 \%$ cellulose and $41.5 \%$ lignin, while bagasse had $42.5 \%$ cellulose and $23.8 \%$ lignin. These values were similar to the results of other research where empty palm fruit bunches were found to contain $27.2 \%$ cellulose and $43.2 \%$ lignin [31]. Phinichka and Kaenthong [32] reported that sugarcane bagasse had $41.4 \%$ cellulose and $19.0 \%$ lignin. Also, the lignin contents of sugarcane bagasse were found to be $25 \%-28 \%$ by Sakdaronnarong et al. [33] and $17 \%-24 \%$ by Masarin et al. [34]. The variety of the chemical composition of original wood samples with the same part and tree type depends on soil conditions, geographic location and climate [35].

Table 1. Appearance of cellulose and CMC from palm bunch and bagasse in different conditions.

\begin{tabular}{|c|c|c|c|c|c|}
\hline \multirow{2}{*}{ Sample } & \multirow{2}{*}{$\begin{array}{c}\text { Unbleached } \\
\left(0 \% \mathrm{H}_{2} \mathrm{O}_{2}\right)\end{array}$} & \multicolumn{4}{|c|}{ Bleached with Various $\mathrm{H}_{2} \mathrm{O}_{2}$ Concentrations $(v / v)$} \\
\hline & & $10 \%$ & $20 \%$ & $30 \%$ & $40 \%$ \\
\hline Cellulose-p & & & & & \\
\hline Code $\rightarrow$ & cellulose-p-0 & cellulose-p-10 & cellulose-p-20 & cellulose-p-30 & cellulose-p-40 \\
\hline Cellulose-b & & & & & \\
\hline Code $\rightarrow$ & cellulose-b-0 & cellulose-b-10 & cellulose-b-20 & cellulose-b-30 & cellulose-b-40 \\
\hline CMCp & & & & & \\
\hline Code $\rightarrow$ & CMCp-0 & CMCp-10 & CMCp-20 & CMCp-30 & $\mathrm{CMCp}-40$ \\
\hline $\mathrm{CMCb}$ & & & & & \\
\hline Code $\rightarrow$ & $\mathrm{CMCb}-0$ & $\mathrm{CMCb}-10$ & $\mathrm{CMCb}-20$ & $\mathrm{CMCb}-30$ & $\mathrm{CMCb}-40$ \\
\hline
\end{tabular}

Diameter of each container is $90 \mathrm{~mm}$. 
The code and appearance of cellulose and CMC from palm bunch and bagasse are listed in Table 1. The letters " $\mathrm{p}$ " and " $\mathrm{b}$ " shown after a code imply the maternal materials palm bunch and bagasse, respectively.

\subsection{Characterization of Cellulose}

In this work, the percent yield of cellulose from palm bunch and bagasse gradually declined when $\mathrm{H}_{2} \mathrm{O}_{2}$ concentration increased (Figure 1a). Palm bunch cellulose loses its weight more than bagasse cellulose after bleaching. This may be because the cellulose of palm bunch has higher lignin content than that of bagasse. The Kappa number $(K)$ was used to indicate the remaining lignin content, implying bleaching ability. Figure $1 b, c$ shows that the trend in $K$ value and lignin content of the bleached cellulose was similar, and this was also related to the trend in percent yield. A similar observation was found with sweet bamboo Kraft pulp by Kamthai and Puthson [36]. The decrease in the yield of cellulose after bleaching may be caused by a decrease in lignin and hemicellulose content [37]. However, at higher levels of $\mathrm{H}_{2} \mathrm{O}_{2}$ concentration or lower $\mathrm{pH}$, the decrease in the yield of cellulose may be because of the depolymerization of cellulose macromolecules to shorter molecules, which are removed more easily from the fiber surface. This observation can be confirmed and further discussed using the SEM results.

The lightness $\left(L^{*}\right)$ and whiteness index $(\mathrm{WI})$ were used as factors affecting the bleaching treatment of the cellulose. These increased with increasing $\mathrm{H}_{2} \mathrm{O}_{2}$ concentrations (Figure 1d,e). This may be because of the bleaching effect of the perhydroxyl anion $\left(\mathrm{HO}_{2}^{-}\right)$[38]. In this study, $\mathrm{H}_{2} \mathrm{O}_{2}$ in aqueous solution was an equilibrium with the $\mathrm{HO}_{2}{ }^{-}$and the peroxo dianion $\left(\mathrm{O}_{2}{ }^{2-}\right)$. In view of the bleaching mechanism, the perhydroxyl anion may generate perhydroxyl radicals $\left(\mathrm{HO}_{2}{ }^{\bullet}\right)$ and further dissociate to create the radical anion $\left(\mathrm{O}_{2}^{-\bullet}\right)$, superoxide. The superoxide is considered one of the active bleaching agents [39].

(a)

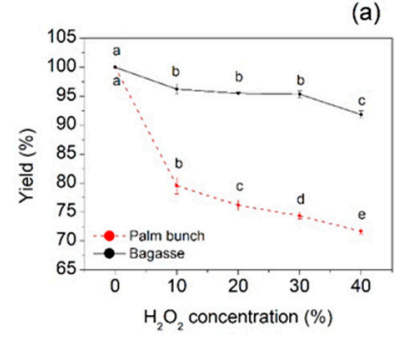

(b)

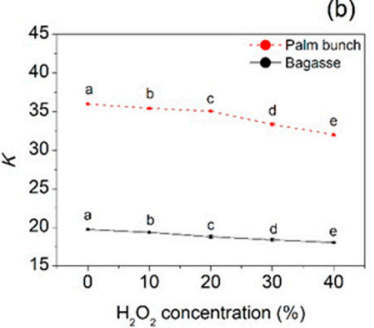

(c)

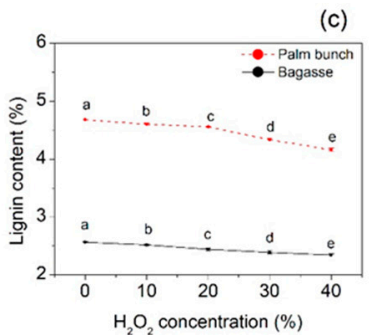

(e)

(d)
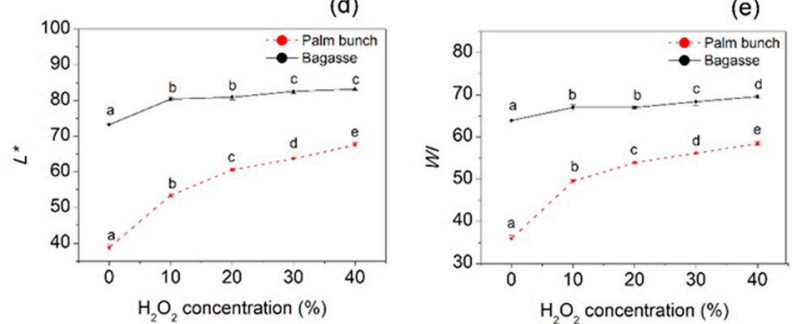

Figure 1. (a) Yield, (b) Kappa number, (c) lignin content and color values, (d) $L^{*}$, and (e) WI of cellulose from palm bunch and bagasse. Abbreviations: $L^{*}$, lightness; WI, whiteness index.

\subsection{Characterization of $C M C$}

$\mathrm{CMC}$ from palm bunch $(\mathrm{CMCp})$ and bagasse $(\mathrm{CMCb})$ was synthesized from their cellulose bleached with various $\mathrm{H}_{2} \mathrm{O}_{2}$ concentrations $(0 \%-40 \%)$. The percent yield of $\mathrm{CMCp}$ ranged from $120.52 \%$ to $135.78 \%$, and that of $\mathrm{CMCb}$ ranged from $135.52 \%$ to $142.41 \%$ (Figure $2 \mathrm{a}$ ). At the beginning, the percent yield of the CMCs increased with increasing $\mathrm{H}_{2} \mathrm{O}_{2}$ concentration $(0 \%-20 \%)$. Nevertheless, it decreased when $\mathrm{H}_{2} \mathrm{O}_{2}$ concentration was over $20 \%$. The highest yield was given by the CMC from $20 \% \mathrm{H}_{2} \mathrm{O}_{2}$-bleached cellulose from both maternal materials. The degree of substitution (DS) of the 
CMCs showed that the trend was related to percent yield (Figure $2 b$ ). The $L^{*}$ and WI values of each CMC were related to its cellulose as a primary material (Figure 2c,d). The DS value of CMCp and $\mathrm{CMCb}$ ranged between $0.17-0.36$ and $0.23-0.53$, respectively. The DS was used to indicate the solubility of the CMC. DS values between 0.0 and 0.4 mean that CMC is insoluble but swellable, and above this range mean that the CMC is completely water-soluble [18]. The highest DS value was found in CMCp and $\mathrm{CMCb}$ made from their respective cellulose and bleached with $20 \% \mathrm{H}_{2} \mathrm{O}_{2}$. Lignocellulosic material is generally composed of cellulose, hemicellulose, and lignin connecting assembly. Lignocellulosic material is generally composed of connected cellulose, hemicellulose, and lignin. Following bleaching with higher $\mathrm{H}_{2} \mathrm{O}_{2}$ concentrations, the cellulose may be more available. Thus, the reaction between the cellulose chain and etherifying agent to generate the CMC may be enhanced. However, at too high a concentration of $\mathrm{H}_{2} \mathrm{O}_{2}$, the cellulose may be depolymerized, which affects the DS decline. Other research has made similar observations to our result, such as work on CMC from Mimosa pigra peel [23], CMC from durian rind [9], and CMC from the waste of cotton ginning [40].

(a)

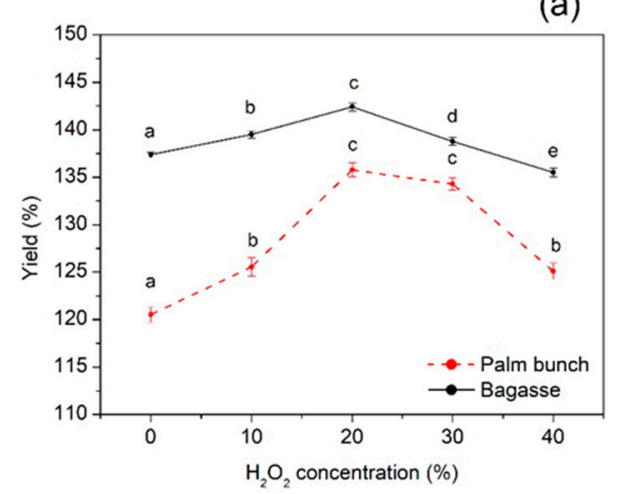

(c)

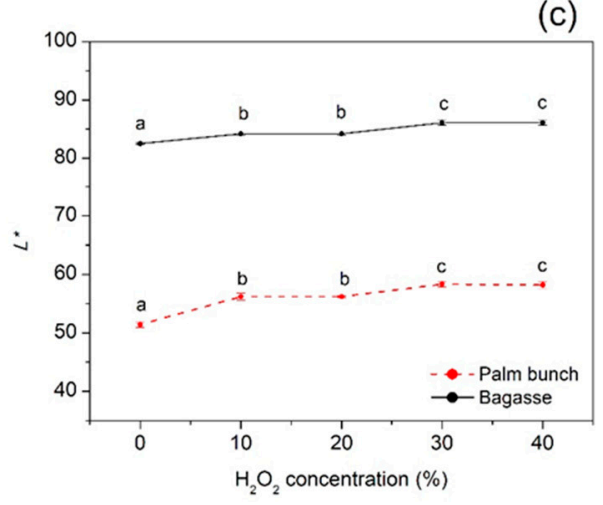

(b)

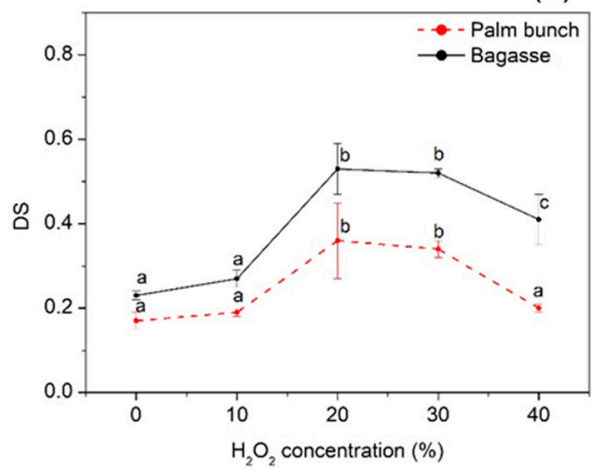

(d)

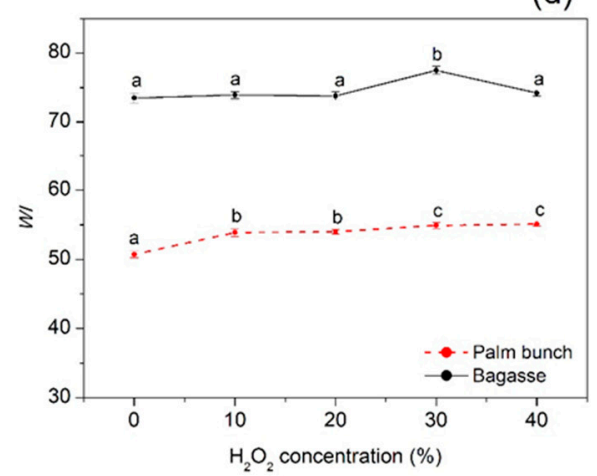

Figure 2. (a) Yield, (b) DS, (c) $L^{*}$, and (d) WI of CMC from palm bunch and bagasse. Abbreviations: DS, degree of substitution; CMC, carboxymethyl cellulose.

It has been found that the viscosity of CMC could be influenced by many factors, such as CMC content [41], sodium hydroxide concentration [9,23], and temperature $[9,23]$. This work focused on the effect of $\mathrm{H}_{2} \mathrm{O}_{2}$ concentration and temperature on the viscosity of $\mathrm{CMCp}$ and $\mathrm{CMCb}$. Figure $3 \mathrm{a}, \mathrm{b}$ presents the viscosity of $\mathrm{CMCp}$ and $\mathrm{CMCb}$, respectively, at 30,40 , and $50^{\circ} \mathrm{C}$. The result shows that the viscosity of each type of $\mathrm{CMCp}$ and $\mathrm{CMCb}$ was lower when the temperature was higher. This is because the higher temperature could enhance the rate of molecular interchange, at the same time as decreasing the cohesive forces, reflecting the lower viscosity. A similar relationship was found for CMC from durian rind [9] and CMC from Mimosa pigra peel [23]. At the same temperature, the trend in viscosity for $\mathrm{CMCp}$ and $\mathrm{CMCb}$ followed the same pattern. It increased with increasing $\mathrm{H}_{2} \mathrm{O}_{2}$ concentrations of up to $20 \%$ and decreased after this point $\left(30 \%-40 \% \mathrm{H}_{2} \mathrm{O}_{2}\right)$, agreeing with the tendency of the DS results mentioned previously. It seems that the viscosity of both CMCs has influences on the DS value. This could be explained by the higher amount of carboxymethyl groups of the CMC having higher DS. 
This could be explained by the higher amount of carboxymethyl groups in CMCs with a larger DS. As we knew, the carboxymethyl group is hydrophilic. Thus, the higher the DS, the more immobilized water achieved in the system $[9,23]$.

(a)

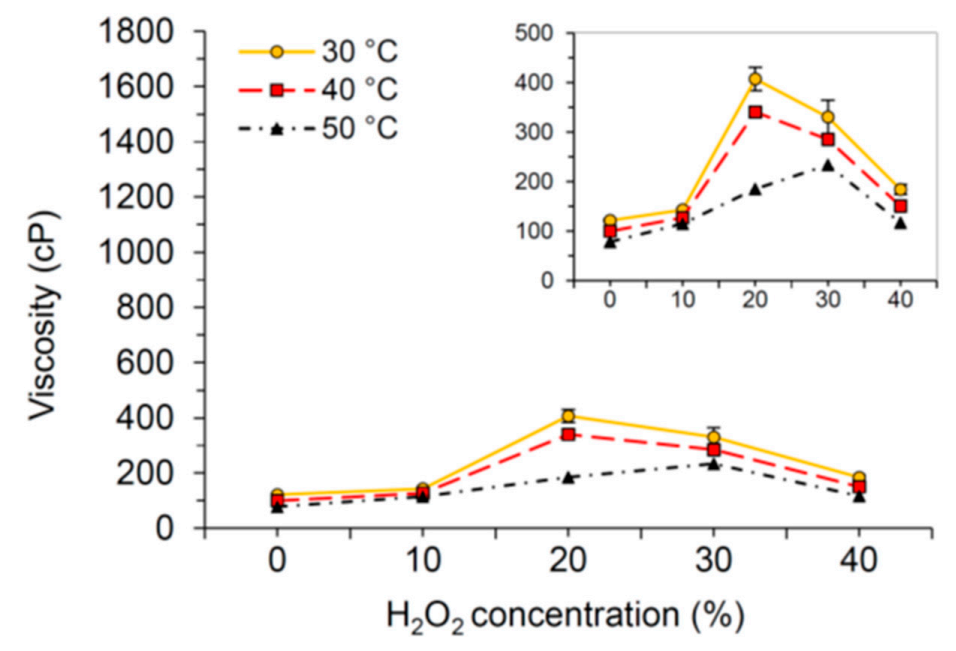

(b)

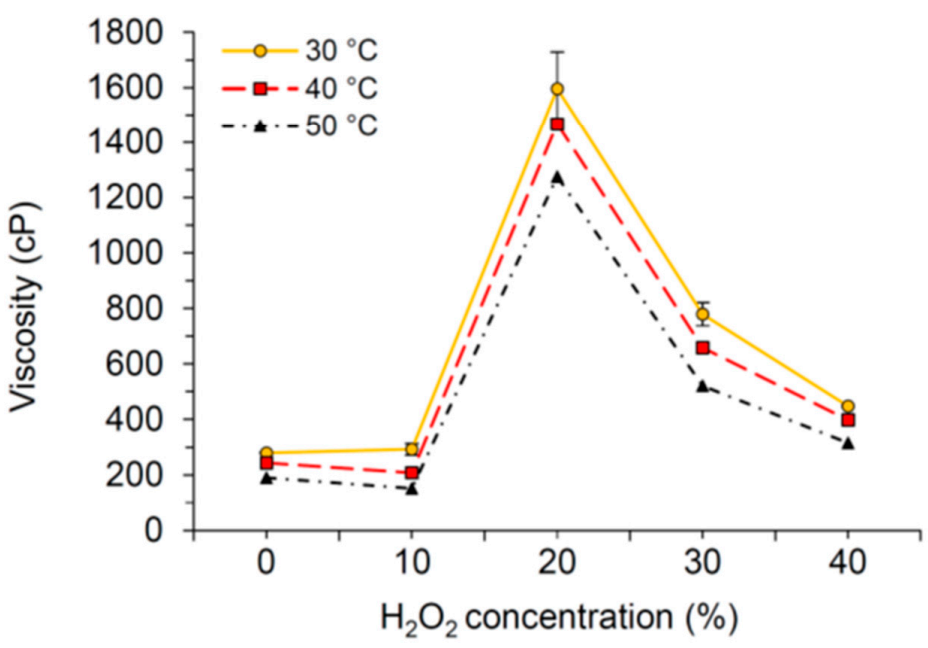

Figure 3. Viscosity of (a) $\mathrm{CMCp}$ and (b) $\mathrm{CMCb}$ at different temperature. Abbreviations: CMCp, $\mathrm{CMC}$ from palm bunch; $\mathrm{CMCb}, \mathrm{CMC}$ from bagasse.

\subsection{Morphology of Cellulose and CMC}

The morphology of raw material, extracted cellulose, and CMC from palm bunch and bagasse was evaluated. Figures $4 \mathrm{a}$ and $5 \mathrm{a}$ represent the SEM micrograph of the lignocellulosic material of palm bunch and bagasse, respectively. The fiber diameter of palm bunch and bagasse was around 80 and $120 \mu \mathrm{m}$, respectively. The fiber was composed of cellulose microfibrils linked with hemicellulose and lignin [42]. Before the extraction of the cellulose, the fiber surface had some substances covering it, which could be lignin and hemicellulose, encrusting the cellulose within [43]. The SEM images of the palm bunch (Figure 4a) and bagasse (Figure 5a) show that the substances covering palm bunch fiber seem to be higher than for that of bagasse, while the surface of the bagasse is clearly smoother than that of the palm bunch in these figures. This result is in agreement with the cellulose and lignin content of 
palm bunch and bagasse previously described in this paper. After extraction and bleaching treatments with various $\mathrm{H}_{2} \mathrm{O}_{2}$ concentrations $(0 \%-40 \%)$, the SEM image of palm bunch cellulose indicated the removal of the encrusting substances from the surfaces of cellulose fiber (Figure $4 b-f)$. Meanwhile, the SEM image of the bagasse cellulosic surface did not show very clear evidence of the removal of those substances (Figure 5b-f). This may be because the bagasse had a low amount of lignin at around $0.5 \times$ compared with that of the palm bunch. However, the approximate lignin level of the cellulose could be calculated using the Kappa number, and it was previously provided in Section 3.1. The results in that section showed that the lignin content of cellulose from both palm bunch and bagasse decreased after bleaching. Figure $4 \mathrm{e}, \mathrm{f}$ and Figure 5e,f noticeably indicate cellulose degradation at too low $\mathrm{pH}$ levels (at 30\%-40\% $\mathrm{H}_{2} \mathrm{O}_{2}$ ) [44]. This observation can be seen as evidence to confirm the character of the cellulose mentioned previously. In Figure $4 \mathrm{~g}-\mathrm{k}$, each CMCp has a smoother surface compared to its maternal material, cellulose. This smooth surface may be attributed to the chemical modification of the cellulose when converting it to CMC. Figure 5g-k shows that the surface of each $\mathrm{CMCb}$ was found to have no residue of encrusting substances. In addition, these CMCs show distorted shapes while their cellulose shows a fiber-like form, except cellulose-b-40. This shape alteration in the CMC may be attributed to chemical modification via CMC synthesis, which was probably found in the CMC synthesized from the cellulose containing low lignin content $(<2.7 \%$ in this study). It was also similar to the morphology result found for sugarcane bagasse by Motaung and Mokhothu [45].
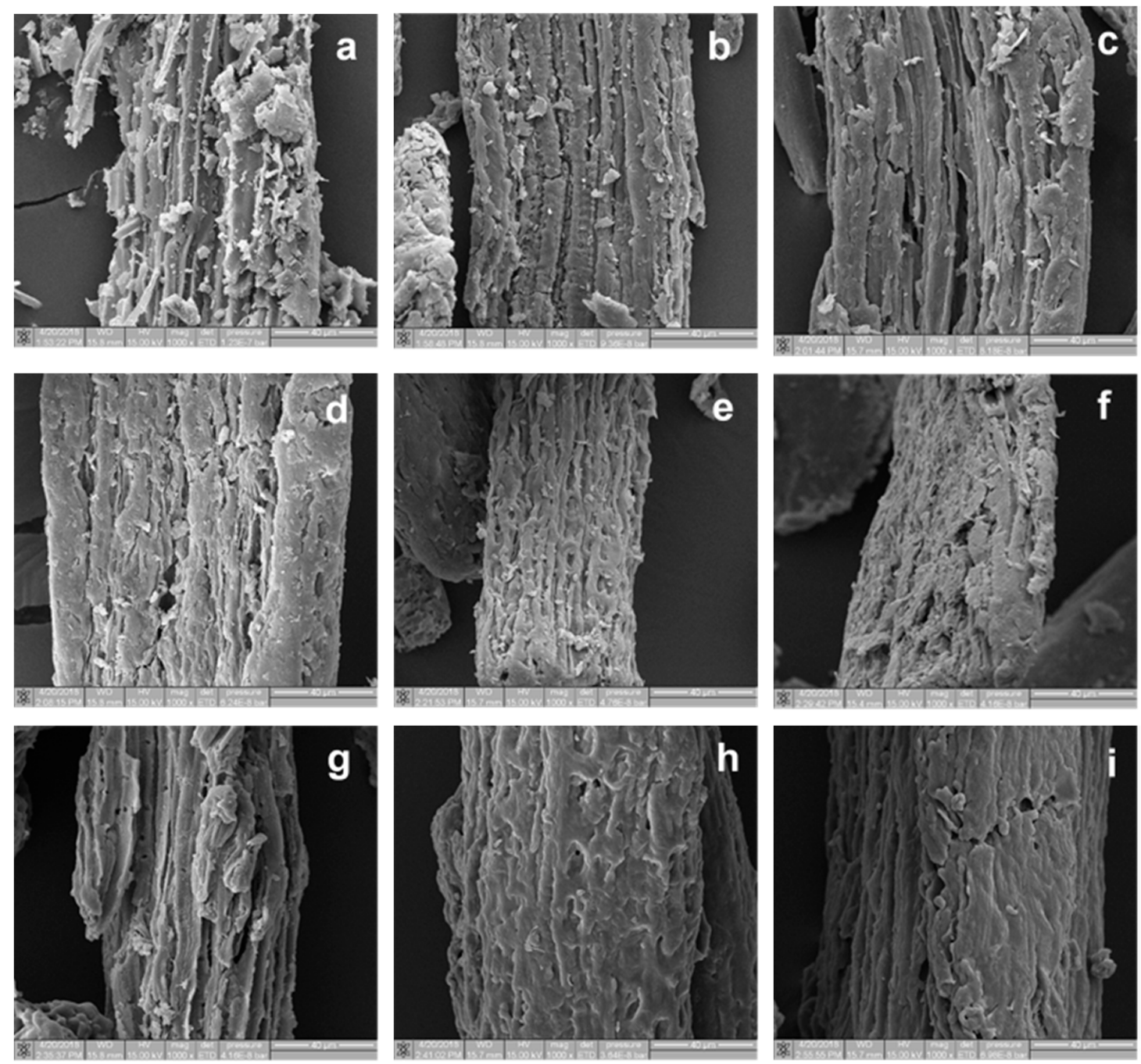

Figure 4. Cont. 

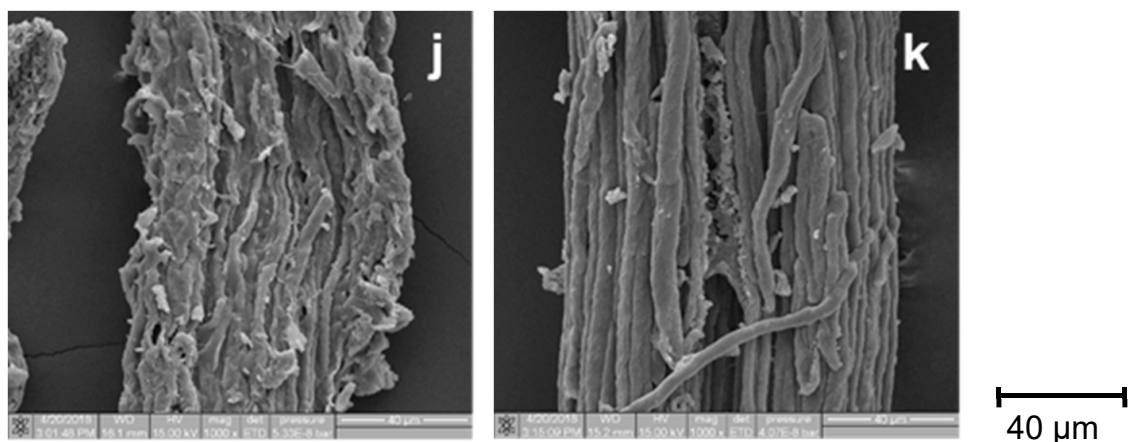

Figure 4. SEM images of (a) palm bunch, (b) cellulose-p-0, (c) cellulose-p-10, (d) cellulose-p-20, (e) cellulose-p-30, (f) cellulose-p-40, (g) CMCp-0, (h) CMCp-10, (i) CMCp-20, (j) CMCp-30, and (k) CMCp-40. Abbreviations: SEM, scanning electron microscope.
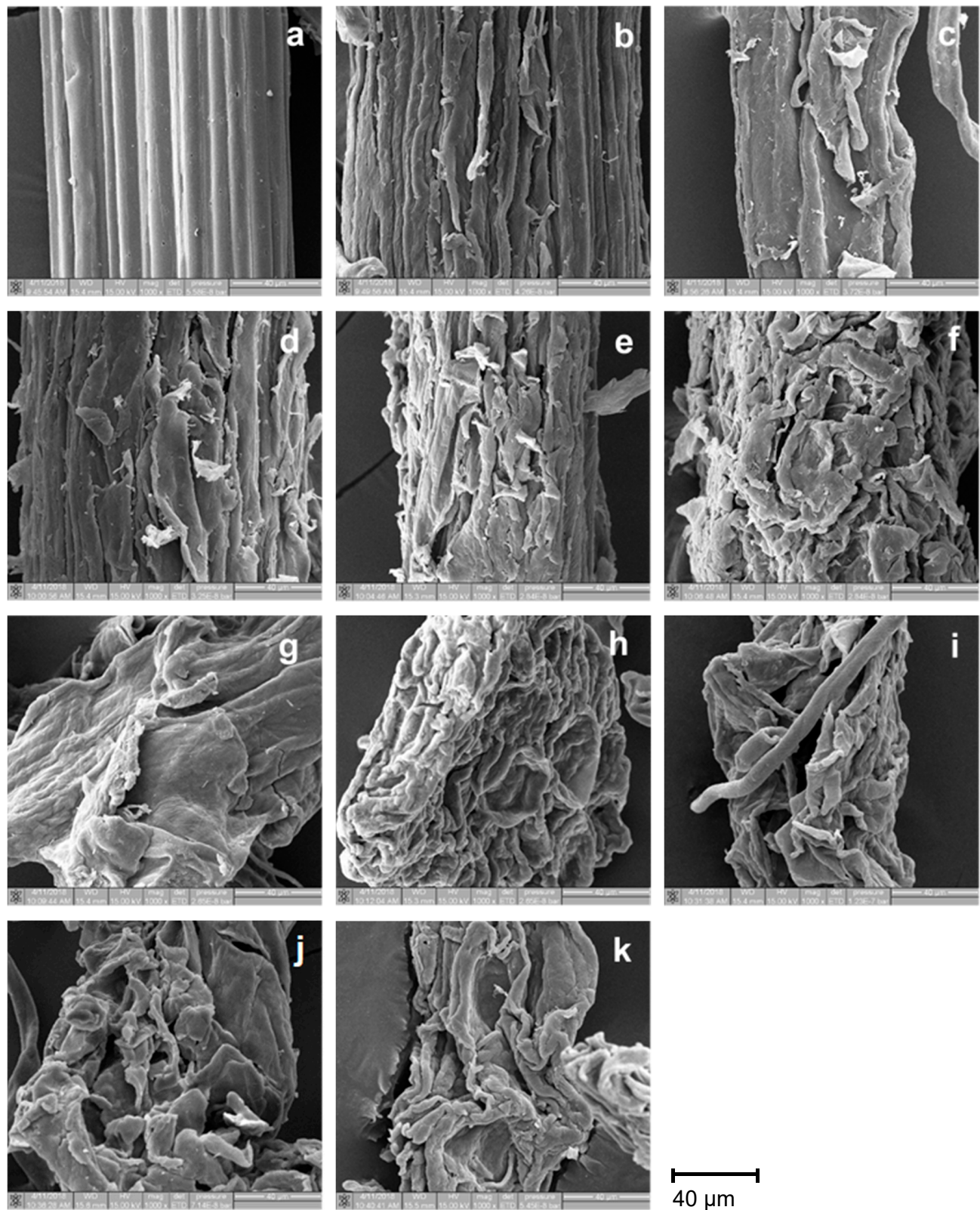

Figure 5. SEM images of (a) bagasse, (b) cellulose-b-0, (c) cellulose-b-10, (d) cellulose-b-20, (e) cellulose-b-30, (f) cellulose-b-40, (g) CMCb-0, (h) CMCb-10, (i) CMCb-20, (j) CMCb-30, and (k) CMCb-40. 


\subsection{FTIR Spectroscopy of Cellulose and CMC}

Because of the superior physical properties of the cellulose and CMC from $20 \% \mathrm{H}_{2} \mathrm{O}_{2}$ bleaching, they were selected to determine the evidence of bleaching and carboxymethylation. The FTIR spectrum of unbleached cellulose of palm bunch (cellulose-p-0) is represented in Figure 6a. The broad band at $3350.3 \mathrm{~cm}^{-1}$ can be attributed to $\mathrm{O}-\mathrm{H}$ stretching, the peak at $2904.8 \mathrm{~cm}^{-1}$ is due to $\mathrm{C}-\mathrm{H}$ stretching, and the peak at $1024.2 \mathrm{~cm}^{-1}$ is ascribed to $-\mathrm{O}-$ stretching [9]. Bands between 1600 and $1370 \mathrm{~cm}^{-1}$ result from lignin, those between 1593.2, 1506.4, and $1421.5 \mathrm{~cm}^{-1}$ from aromatic phenylpropane skeleton vibrations, and those at $1369.4 \mathrm{~cm}^{-1}$ from phenolic hydroxyl groups [46]. For the bleached cellulose from palm bunch (cellulose-p-20), the spectra were similar to the cellulose-p-0. However, the absorbance of the bands between 1600 and $1370 \mathrm{~cm}^{-1}$ seemed to decrease indicating the decrease of lignin content in the cellulose structure.

The FTIR spectrum of unbleached cellulose of bagasse (cellulose-b-0) is represented in Figure $6 \mathrm{~b}$. The broad band at $3336.8 \mathrm{~cm}^{-1}$ is due to $\mathrm{O}-\mathrm{H}$ stretching. The peaks at 2891.3 and $1022.6 \mathrm{~cm}^{-1}$ are due to $\mathrm{C}-\mathrm{H}$ stretching and $-\mathrm{O}-$ stretching, respectively. The peak at $1641.4 \mathrm{~cm}^{-1}$ results from the $\mathrm{O}-\mathrm{H}$ bending of water [8,24]. The bands at 1421.5 and $1367.5 \mathrm{~cm}^{-1}$ can be attributed to the aromatic phenylpropane skeleton vibrations and phenolic hydroxyl groups, respectively, of lignin. When comparing the spectra of cellulose-b-0 with the bleached cellulose from bagasse (cellulose-b-20), the result is in agreement with the result found in palm bunch. The slight decrease in the absorbance of the bands of lignin confirms the decreasing lignin content after bleaching.

For CMCp and $\mathrm{CMCb}$, the FTIR spectrum shows that the frequency of the absorption bands was similar to those of their respective cellulose. This implies that cellulose and CMC have similar functional groups (Figure 6a,b). Additionally, the peaks at $1325.1 \mathrm{~cm}^{-1}$ for CMCp-20 and at $1323.2 \mathrm{~cm}^{-1}$ for $\mathrm{CMCb}-20$ can be attributed to $-\mathrm{OH}$ bending vibration [20]. The absorption bands at 1591.3 and $1419.6 \mathrm{~cm}^{-1}$ for CMCp-20, and at 1587.4 and $1413.8 \mathrm{~cm}^{-1}$ for $\mathrm{CMCb}-20$, were respectively due to antisymmetric and symmetric stretching vibrations of the COO- group $[10,24]$. This indicates the substitution of carboxymethyl groups on the cellulose structure.

(a)

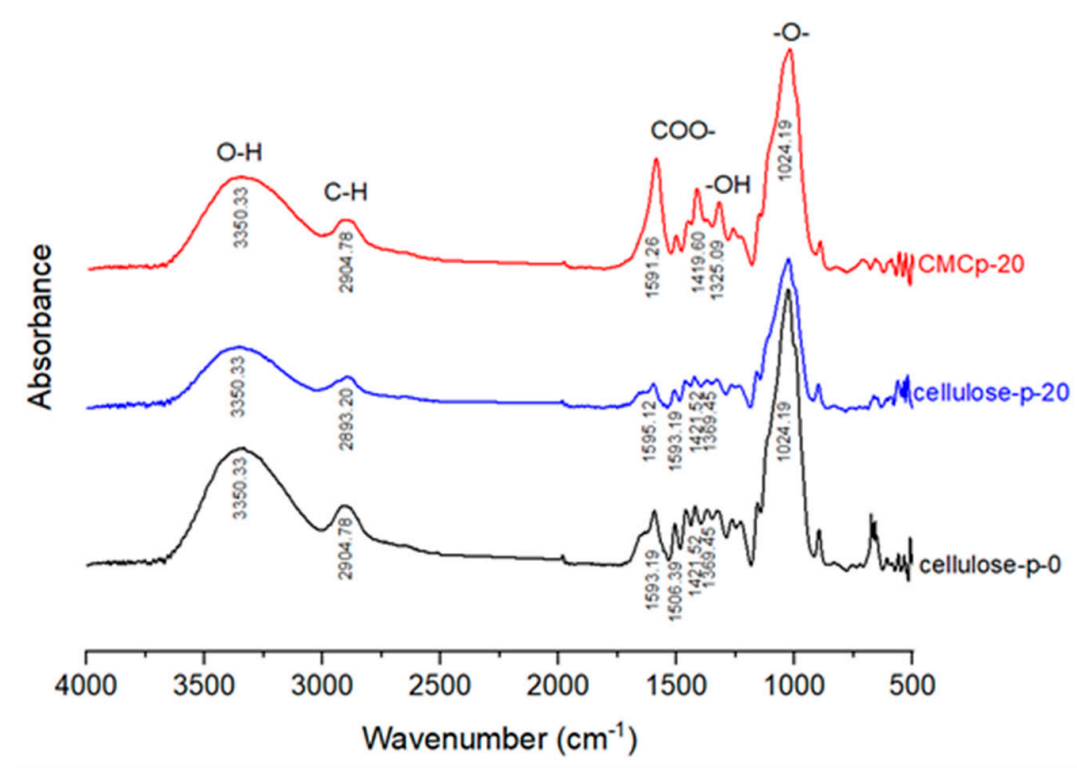

Figure 6. Cont. 
(b)

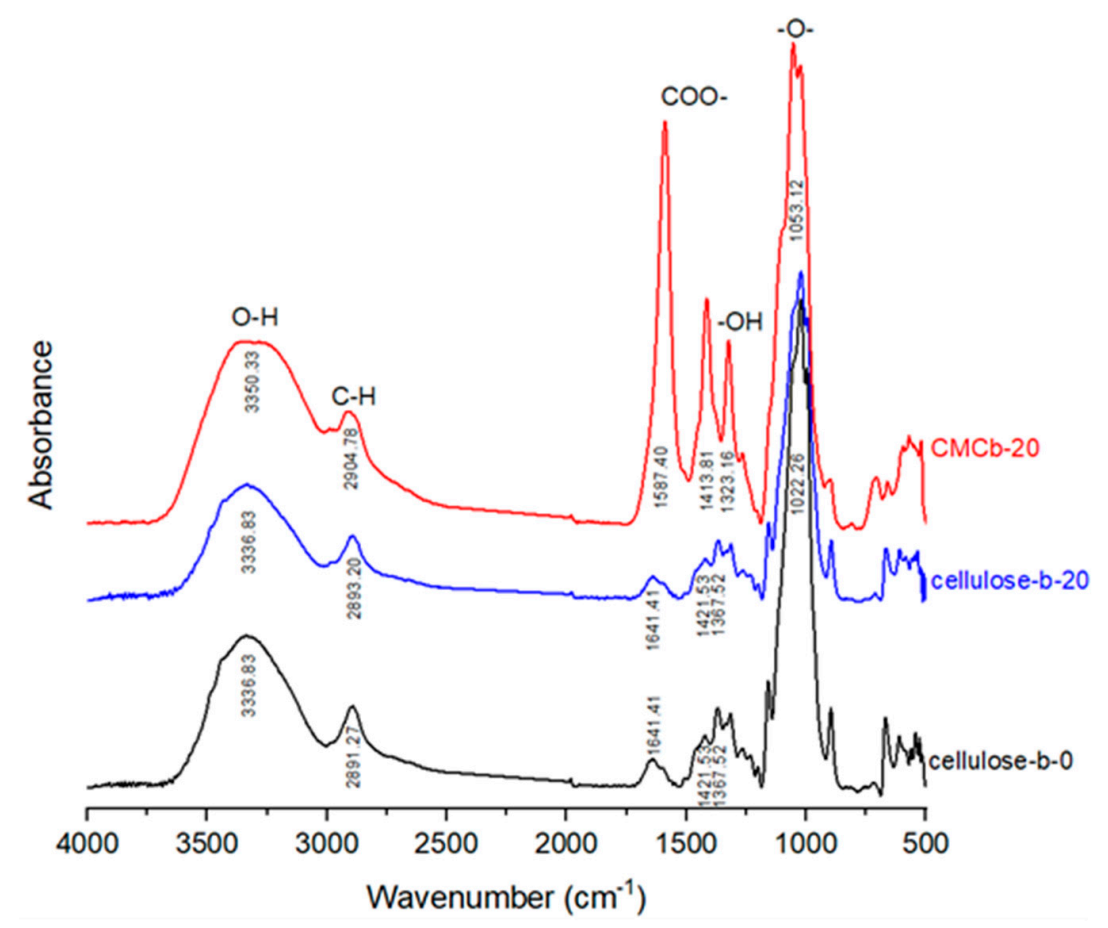

Figure 6. FTIR spectra of cellulose and CMC from (a) palm bunch and (b) bagasse.

\subsection{Characterization of CMC Films}

In this section, $\mathrm{CMC}$ film from each type of $\mathrm{CMCp}$ and $\mathrm{CMCb}$ was produced, and its properties were investigated. The thickness of CMCp and CMCb films ranged between 0.127 and $0.213 \mathrm{~mm}$, and between 0.081 and $0.111 \mathrm{~mm}$, respectively. Table 2 lists the $L^{*}$ and WI values, mechanical properties, solubility, and water barrier of these CMC films. The $L^{*}$ and WI values of the films related to those of the CMCs. It was found that $\mathrm{H}_{2} \mathrm{O}_{2}$ concentration affected the tensile strength (TS), elongation at break (EB), solubility, and water vapor transmission rate (WVTR) of CMCp and CMCb films. Interestingly, the results seemed to correlate with the DS previously described in this document. Bleaching cellulose with $20 \% \mathrm{H}_{2} \mathrm{O}_{2}$ appeared to yield the highest values of TS, solubility and WVTR for both CMC films. In terms of TS, it could be explained by the fact that the more carboxymethyl groups CMC occupied, the more intermolecular forces within the polymer chains resulted in an enhanced TS of the film [23]. The difference in strength between the $\mathrm{CMCp}$ and $\mathrm{CMCb}$ films depends on the relative content of their cellulose and lignin [42]. The EB of the film relates to its flexibility. In the bleaching process and CMC synthesis, the crystallinity of cellulose structure is altered and decreased $[9,10]$. This decrease in the crystalline region affects the increasing flexibility of the CMC film. For CMCp, when $\mathrm{H}_{2} \mathrm{O}_{2}$ was above $20 \%$, the EB was likely to decline gradually. This may be because cellulose degrades with higher acid levels before converting to CMC. Nevertheless, the EB of CMCb was not significantly different when the $\mathrm{H}_{2} \mathrm{O}_{2}$ varied from $10 \%$ to $40 \%$. This is because crystallinity may not be altered for the group of the $\mathrm{CMCb}$. In the meantime, our solubility and WVTR results are in agreement with the results for CMC from bagasse pulp [47] and CMC from durian rind [9]. The rising DS value allowed the higher solubility and WVTR of the CMC films. This may be because of the hydrophilicity of carboxymethyl groups. 
Table 2. Physical properties of the films from CMCp and $\mathrm{CMCb}$

\begin{tabular}{|c|c|c|c|c|c|c|c|c|}
\hline Film & $\begin{array}{c}\mathrm{H}_{2} \mathrm{O}_{2} \\
(\% v / v)\end{array}$ & $\begin{array}{l}\text { Thickness } \\
(\mathrm{mm})\end{array}$ & $L^{*}$ & WI & $\begin{array}{c}\text { TS } \\
(\mathrm{MPa})\end{array}$ & $\begin{array}{l}\text { EB } \\
(\%)\end{array}$ & $\begin{array}{l}\text { Solubility } \\
(\%)\end{array}$ & $\begin{array}{l}\text { WVTR } \\
\left.\text { (g/d.m }{ }^{2}\right)\end{array}$ \\
\hline \multirow{5}{*}{ CMCp } & 0 & $0.213 \pm 0.052^{a}$ & $50.3 \pm 0.3^{a}$ & $44.9 \pm 0.5^{\mathrm{a}}$ & $5.68 \pm 1.67^{\mathrm{a}}$ & $56.18 \pm 26.17^{a b}$ & $28.44 \pm 5.51^{a}$ & $58.15 \pm 4.45^{\mathrm{a}}$ \\
\hline & 10 & $0.136 \pm 0.006^{b c}$ & $60.2 \pm 0.4^{b}$ & $47.6 \pm 0.6^{b}$ & $7.77 \pm 0.45^{b}$ & $68.73 \pm 8.85^{b}$ & $34.85 \pm 2.40^{b}$ & $58.23 \pm 4.43^{a}$ \\
\hline & 20 & $0.127 \pm 0.011^{b}$ & $70.0 \pm 0.7^{\mathrm{d}}$ & $53.9 \pm 0.9^{c}$ & $8.28 \pm 1.06^{b}$ & $68.42 \pm 7.57^{b}$ & $45.81 \pm 1.36^{\mathrm{c}}$ & $74.47 \pm 8.93^{b}$ \\
\hline & 30 & $0.144 \pm 0.030 b c$ & $70.1 \pm 0.4^{\mathrm{d}}$ & $56.4 \pm 0.6^{\mathrm{d}}$ & $3.96 \pm 1.14^{c}$ & $46.86 \pm 14.44^{\mathrm{a}}$ & $43.51 \pm 3.78^{c}$ & $61.77 \pm 7.24^{\mathrm{a}}$ \\
\hline & 40 & $0.156 \pm 0.030^{c}$ & $68.9 \pm 0.4^{c}$ & $57.1 \pm 0.7^{\mathrm{d}}$ & $1.41 \pm 0.68^{\mathrm{d}}$ & $42.86 \pm 5.78 \mathrm{a}$ & $36.70 \pm 1.91^{b}$ & $55.92 \pm 7.23^{a}$ \\
\hline \multirow{5}{*}{$\mathrm{CMCb}$} & 0 & $0.111 \pm 0.011^{a}$ & $85.3 \pm 0.2^{a}$ & $81.5 \pm 0.4^{\mathrm{a}}$ & $13.94 \pm 1.10^{a}$ & $79.08 \pm 12.59^{a}$ & $36.12 \pm 2.58^{a}$ & $46.28 \pm 0.74^{a}$ \\
\hline & 10 & $0.083 \pm 0.010^{b}$ & $86.2 \pm 0.2^{b}$ & $84.6 \pm 0.4^{b}$ & $16.91 \pm 4.11^{b}$ & $86.64 \pm 22.67^{b}$ & $37.70 \pm 1.06^{\mathrm{a}}$ & $51.72 \pm 4.64^{\mathrm{ab}}$ \\
\hline & 20 & $0.081 \pm 0.007^{b}$ & $86.2 \pm 0.2^{b}$ & $84.1 \pm 0.4^{b}$ & $29.09 \pm 3.35^{c}$ & $84.92 \pm 7.74^{b}$ & $66.65 \pm 1.94^{b}$ & $62.94 \pm 11.97^{b}$ \\
\hline & 30 & $0.089 \pm 0.014^{b}$ & $86.3 \pm 0.4^{b}$ & $84.5 \pm 0.3^{b}$ & $17.96 \pm 2.68^{b}$ & $84.18 \pm 11.10^{b}$ & $65.94 \pm 3.99^{b}$ & $48.63 \pm 11.13^{a b}$ \\
\hline & 40 & $0.088 \pm 0.008^{b}$ & $86.6 \pm 0.1^{b}$ & $85.4 \pm 0.8^{c}$ & $16.86 \pm 3.03^{b}$ & $84.20 \pm 11.41^{b}$ & $44.19 \pm 1.28^{c}$ & $45.74 \pm 1.94^{\mathrm{a}}$ \\
\hline
\end{tabular}

Values within a column in the same group followed by the same letter are not significantly different $(p>0.05)$. 


\section{Conclusions}

Cellulose extracted from palm bunch and bagasse could be bleached with various concentrations of hydrogen peroxide $\left(\mathrm{H}_{2} \mathrm{O}_{2}\right)$. Moreover, the products after bleaching could be utilized as the main raw material in the synthesis of carboxymethyl cellulose (CMC) by etherification between the cellulose and chloroacetic acid under alkaline conditions. The results showed that to receive CMC with a high yield, degree of substation, and viscosity, the $\mathrm{H}_{2} \mathrm{O}_{2}$ concentration should be should be properly operated. To obtain a CMC film with high mechanical properties (tensile strength and elongation at break), solubility, and water vapor transmission rate, the $\mathrm{H}_{2} \mathrm{O}_{2}$ concentration should be controlled as well. It was also demonstrated that, in this work, bleaching cellulose with $20 \% \mathrm{H}_{2} \mathrm{O}_{2}$ resulted in the synthesized CMC products and films with the best physical properties.

Author Contributions: Conception and design of the experiments, P.R.; conceptualization, P.R.; investigation and methodology, N.N., T.K., P.R.; writing_original draft preparation, R.S., N.N., T.K.; writing-review and editing, R.S., K.J., N.L., Y.P., C.I., P.S., T.C., P.J., S.R.S., T.M.P.N., P.R.; analysis of data, R.S. and P.R.; contribution of reagents/materials, P.R.; validation, P.S., P.R.; funding acquisition, P.R.; supervision, P.R. All authors have read and agreed to the published version of the manuscript.

Funding: This research was partially supported by Chiang Mai University. We wish to thank the Center of Excellence in Materials Science and Technology for financial support under the administration of the Materials Science Research Center, Faculty of Science, Chiang Mai University.

Acknowledgments: This research work was partially supported by Chiang Mai University. We wish to thank the Center of Excellence in Materials Science and Technology for financial support under the administration of the Materials Science Research Center, Faculty of Science, Chiang Mai University.

Conflicts of Interest: The authors declare no conflict of interest.

\section{References}

1. Yu, J.; Yang, J.; Zeng, Q.; Huang, Y. Effect of carboxymethyl cellulose addition on the properties of Si3N4 ceramic foams. Ceram. Int. 2013, 39, 2775-2779. [CrossRef]

2. Tarrés, Q.; Oliver-Ortega, H.; Alcalà, M.; Merayo, N.; Balea, A.; Blanco, Á.; Mutjé, P.; Delgado-Aguilar, M. Combined effect of sodium carboxymethyl cellulose, cellulose nanofibers and drainage aids in recycled paper production process. Carbohydr. Polym. 2018, 183, 201-206. [CrossRef] [PubMed]

3. Fijan, R.; Basile, M.; Šostar-Turk, S.; Žagar, E.; Žigon, M.; Lapasin, R. A study of rheological and molecular weight properties of recycled polysaccharides used as thickeners in textile printing. Carbohydr. Polym. 2009, 76, 8-16. [CrossRef]

4. Singh, V.; Joshi, S.; Malviya, T. Carboxymethyl cellulose-rosin gum hybrid nanoparticles: An efficient drug carrier. Int. J. Biol. Macromol. 2018, 112, 390-398. [CrossRef] [PubMed]

5. Schuh, V.; Allard, K.; Herrmann, K.; Gibis, M.; Kohlus, R.; Weiss, J. Impact of carboxymethyl cellulose (CMC) and microcrystalline cellulose (MCC) on functional characteristics of emulsified sausages. Meat Sci. 2013, 93, 240-247. [CrossRef]

6. Ma, X.; Chang, P.R.; Yu, J. Properties of biodegradable thermoplastic pea starch/carboxymethyl cellulose and pea starch/microcrystalline cellulose composites. Carbohydr. Polym. 2008, 72, 369-375. [CrossRef]

7. Tongdeesoontorn, W.; Mauer, L.; Wongruong, S.; Sriburi, P.; Rachtanapun, P. Effect of carboxymethyl cellulose concentration on physical properties of biodegradable cassava starch-based films. Chem. Cent. J. 2011, 5, 1-8. [CrossRef]

8. Mauricio, Y.; Matsuhiro, B.; Maldonado, S.; González, R.; Luengo, J.; Uyarte, O.; Serafine, D.; Moya, S.; Romero, J.; Torres, R.; et al. Carboxymethylcellulose from bleached organosolv fibers of Eucalyptus nitens: Synthesis and physicochemical characterization. Cellulose 2018, 25, 2901-2914. [CrossRef]

9. Rachtanapun, P.; Luangkamin, S.; Tanprasert, K.; Suriyatem, R. Carboxymethyl cellulose film from durian rind. LWT-Food Sci. Technol. 2012, 48, 52-58. [CrossRef]

10. Adinugraha, M.P.; Marseno, D.W.; Hayadi. Synthesis and characterization of sodium carboxymethylcellulose from cavendish banana pseudo stem (Musa cavendishii LAMBERT). Carbohydr. Polym. 2005, 62, 164-169. [CrossRef] 
11. Križman, P.; Kovač, F.; Tavčer, P.F. Bleaching of cotton fabric with peracetic acid in the presence of different activators. Color. Technol. 2005, 121, 304-309. [CrossRef]

12. Rachtanapun, P.; Eitssayeam, S.; Pengpat, K. Study of carboxmethyl cellulose from papaya peels binder in ceramics. Adv. Mat. Res. 2010,93-94, 17-21.

13. Rayung, M.; Ibrahim, N.A.; Zainuddin, N.; Saad, W.Z.; Razak, N.I.A.; Chieng, B.W. The effect of fiber bleaching treatment on the properties of poly(lactic acid)/oil palm empty fruit bunch fiber composites. Int. J. Mol. Sci. 2014, 15, 14728-14742. [CrossRef]

14. Topalovic, T.; Nierstrasz, V.A.; Bautista, L.; Jocic, D.; Navarro, A.; Warmoeskerken, M.M.C.G. Analysis of the effects of catalytic bleaching on cotton. Cellulose 2007, 14, 385-400. [CrossRef]

15. Henniges, U.; Potthast, A. Bleaching Revisited: Impact of Oxidative and Reductive Bleaching Treatments on Cellulose and Paper. Restaurator 2009, 30, 294-320. [CrossRef]

16. Abdel-Halim, E.S.; Alanazi, H.H.; Alghamdi, A.A. Extraction and bleaching of olive tree branch cellulose. BioResources 2015, 10, 7136-7150. [CrossRef]

17. Jannah, M.; Ahmad, A.; Hayatun, A.; Taba, P.; Chadijah, S. Effect of filler and plastisizer on the mechanical properties of bioplastic cellulose from rice husk. J. Phys. Conf. Ser. 2019, 1341. [CrossRef]

18. Togrul, H.; Arslan, N. Production of carboxymethyl cellulose from sugar beet pulp cellulose and rheological behavior of carboxymethyl cellulose. Carbohydr. Polym. 2003, 54, 73-82. [CrossRef]

19. Lin, X.; Qu, T.; Qi, S. Kinetics of the carboxymethyl cellulose in the isopropyl alcohol system. Acta Polym. 1990, 41, 220.

20. Pushpamalar, V.; Langford, S.J.; Ahmad, M.; Lim, Y.Y. Optimization of reaction conditions for preparing carboxymethylcellulose from sago waste. Carbohydr. Polym. 2006, 64, 312-318. [CrossRef]

21. Rachtanapun, P.; Kumthai, S.; Mulkarat, N.; Pintajam, N.; Suriyatem, R. Value added of mulberry paper waste by carboxymethylation for preparation a packaging film. IOP Conf. Ser. Mater. Sci. Eng. 2015, 87, 012081. [CrossRef]

22. Mondal, M.I.H.; Yeasmin, M.S.; Rahman, M.S. Preparation of food grade carboxymethyl cellulose from corn husk agrowaste. Int. J. Biol. Macromol. 2015, 79, 144-150. [CrossRef] [PubMed]

23. Rachtanapun, P.; Rattanapanone, N. Synthesis and characterization of carboxymethyl cellulose powder and films from Mimosa pigra. J. Appl. Polym. Sci. 2011, 122, 3218-3226. [CrossRef]

24. Suriyatem, R.; Auras, R.A.; Rachtanapun, P. Utilization of Carboxymethyl Cellulose from Durian Rind Agricultural Waste to Improve Physical Properties and Stability of Rice Starch-Based Film. J. Polym. Environ. 2019, 27, 286-298. [CrossRef]

25. TAPPI. Alpha-, Beta- and Gamma-Cellulose in Pulp. In Test Method T $203 \mathrm{~cm}-09$, 2009. Available online: https://imisrise.tappi.org/TAPPI/Products/01/T/0104T203.aspx (accessed on 11 June 2020).

26. TAPPI. Acid-Insoluble Lignin in Wood and Pulp. In Test Method T 222 om-15, 2015. Available online: https://www.techstreet.com/standards/tappi-t-222-om-15?product_id=2000142 (accessed on 11 June 2020).

27. TAPPI. Kappa Number of Pulp. In Test Method T 236 om-99, 1999. Available online: https://research.cnr. ncsu.edu/wpsanalytical/documents/T236.PDF (accessed on 11 June 2020).

28. Suriyatem, R.; Auras, R.A.; Rachtanapun, P. Improvement of mechanical properties and thermal stability of biodegradable rice starch-based films blended with carboxymethyl chitosan. Ind. Crop. Prod. 2018, 122, 37-48. [CrossRef]

29. ASTM-D882-12. Standard Test Method for Tensile Properties of Thin Plastic Sheeting; ASTM International: West Conshohocken, PA, USA, 2012. Available online: https://www.scribd.com/document/383783567/ASTM-D88212 (accessed on 11 June 2020).

30. ASTM-E96/E9M-16. Standard Test Methods for Water Vapor Transmission of Materials; ASTM International: West Conshohocken, PA, USA, 2016. Available online: https://www.astm.org/Standards/E96 (accessed on 11 June 2020).

31. Coral Medina, J.D.; Woiciechowski, A.; Zandona Filho, A.; Noseda, M.D.; Kaur, B.S.; Soccol, C.R. Lignin preparation from oil palm empty fruit bunches by sequential acid/alkaline treatment-A biorefinery approach. Bioresour. Technol. 2015, 194, 172-178. [CrossRef]

32. Phinichka, N.; Kaenthong, S. Regenerated cellulose from high alpha cellulose pulp of steam-exploded sugarcane bagasse. J. Mater. Res. Technol. 2018, 7, 55-65. [CrossRef] 
33. Sakdaronnarong, C.K.; Onsrithong, N.; Suwankrua, R.; Jonglertjunya, W. Improving enzymatic saccharification of sugarcane bagasse by biological/physico-chemical pretreatment using Trametes versicolor and Bacillus sp. Bioresour. Bioprocess. 2012, 7, 3935-3947.

34. Masarin, F.; Gurpilhares, D.B.; Baffa, D.C.; Barbosa, M.H.; Carvalho, W.; Ferraz, A.; Milagres, A.M. Chemical composition and enzymatic digestibility of sugarcane clones selected for varied lignin content. Biotechnol. Biofuels 2011, 4, 55. [CrossRef]

35. Pettersen, R.C. The Chemical Composition of Wood. In The Chemistry of Solid Wood; American Chemical Society: Washington, DC, USA, 1984; Volume 207, pp. 57-126.

36. Kamthai, S.; Puthson, P. Effect of beating revolution on sweet bamboo Kraft pulp properties. CMU J. 2005, 4, 137-147.

37. Baksi, S.; Saha, S.; Birgen, C.; Sarkar, U.; Preisig, H.A.; Markussen, S.; Wittgens, B.; Wentzel, A. Valorization of Lignocellulosic Waste (Crotalaria juncea) Using Alkaline Peroxide Pretreatment under Different Process Conditions: An Optimization Study on Separation of Lignin, Cellulose, and Hemicellulose. J. Nat. Fibers 2019, 16, 662-676. [CrossRef]

38. Abdel-Halim, E.S.; Al-Deyab, S.S. One-step bleaching process for cotton fabrics using activated hydrogen peroxide. Carbohydr. Polym. 2013, 92, 1844-1849. [CrossRef] [PubMed]

39. Zahran, M.K. One-step process for desizing, scouring and bleaching of cotton fabric using a novel ecofriendly bleaching agent. J. Text. Assoc. 2006, 67, 153-158.

40. Haleem, N.; Arshad, M.; Shahid, M.; Tahir, M.A. Synthesis of carboxymethyl cellulose from waste of cotton ginning industry. Carbohydr. Polym. 2014, 113, 249-255. [CrossRef] [PubMed]

41. El Ghzaour, A.; Trompette, J.L.; Cassanas, G.; Bardet, L.; Fabregue, E. Comparative rheological behavior of some cellulosic ether derivatives. Langmuir 2001, 17, 1453-1456. [CrossRef]

42. Monteiro, S.N.; Lopes, F.P.D.; Barbosa, A.P.; Bevitori, A.B.; Silva, I.L.A.D.; Costa, L.L.D. Natural Lignocellulosic Fibers as Engineering Materials-An Overview. Metall. Mater. Trans. A 2011, 42, 2963-2974. [CrossRef]

43. Mohtar, S.S.; Tengku Malim Busu, T.N.Z.; Md Noor, A.M.; Shaari, N.; Mat, H. An ionic liquid treatment and fractionation of cellulose, hemicellulose and lignin from oil palm empty fruit bunch. Carbohydr. Polym. 2017, 166, 291-299. [CrossRef]

44. Qi, H.; Liebert, T.; Meister, F.; Heinze, T. Homogenous carboxymethylation of cellulose in the $\mathrm{NaOH} / \mathrm{urea}$ aqueous solution. React. Funct. Polym. 2009, 69, 779-784. [CrossRef]

45. Motaung, T.E.; Mokhothu, T.H. The influence of supermasscolloider on the morphology of sugarcane bagasse and bagasse cellulose. Fibers Polym. 2016, 17, 343-348. [CrossRef]

46. Alriols, M.G.; Tejado, A.; Blanco, M.; Mondragon, I.; Labidi, J. Agricultural palm oil tree residues as raw material for cellulose, lignin and hemicelluloses production by ethylene glycol pulping process. Chem. Eng. J. 2009, 148, 106-114. [CrossRef]

47. Kamthai, S.; Magaraphan, R. Mechanical and barrier properties of spray dried carboxymethyl cellulose (CMC) film from bleached bagasse pulp. Ind. Crop. Prod. 2017, 109, 753-761. [CrossRef]

(C) 2020 by the authors. Licensee MDPI, Basel, Switzerland. This article is an open access article distributed under the terms and conditions of the Creative Commons Attribution (CC BY) license (http://creativecommons.org/licenses/by/4.0/). 